\title{
Follistatin-like protein 1 knockdown elicits human gastric cancer cell apoptosis via a STAT6-dependent pathway
}

\author{
XINGANG PENG ${ }^{1,2}$, PEIGE WANG ${ }^{2}$, SHIKUAN LI $^{2}$, YINGJUN JIANG ${ }^{2}$ and CHANGLIANG WU ${ }^{2}$ \\ ${ }^{1}$ Department of General Surgery, Qilu Hospital of Shandong University, \\ Jinan, Shandong 250012; ${ }^{2}$ Department of Emergency General Surgery, \\ The Affiliated Hospital of Qingdao University, Qingdao, Shandong 266555, P.R. China
}

Received March 31, 2018; Accepted August 10, 2018

DOI: $10.3892 / o r .2019 .7334$

\begin{abstract}
Gastric cancer is an aggressive disease and a common cause of cancer-associated mortality worldwide. Recent studies have indicated that follistatin-like protein 1 (FSTL-1) is expressed and serves essential roles in tumorigenesis; however, the specific functional mechanism of FSTL-1 in gastric cancer progression remains ambiguous. CellTiter-Glo Luminescent Cell Viability and lactate dehydrogenase assays were used to measure cell survival and cell cytotoxicity, respectively. Cell apoptosis was ascertained using the Cell Death Detection ELISA assay and caspase-3/9 activity kits. Reverse transcription-quantitative polymerase chain reaction and western blotting were used to detect the expression levels of FSTL-1. The present study confirmed that FSTL-1 was highly expressed in gastric cancer cells compared with in control cells. Subsequently, FSTL-1 inhibition by small interfering RNA significantly reduced cancer cell survival and induced cytotoxic effects. In addition, knockdown of FSTL-1 in gastric cancer cells promoted apoptosis by increasing caspase- 3 and caspase- 9 expression. A decrease in signal transducer and activator of transcription 6 (STAT6) phosphorylation was observed in FSTL-1 knockdown cells, and the results confirmed that STAT6 phosphorylation was essential for FSTL-1 knockdown-induced cell apoptosis of cancer cells. Taken together, these results demonstrated that FSTL-1 knockdown may promote cell apoptosis via the STAT6 signaling pathway; therefore, FSTL1 may be considered a novel diagnostic and therapeutic target for gastric cancer.
\end{abstract}

\section{Introduction}

Gastric cancer is an aggressive disease and a common cause of cancer-associated mortality worldwide. The highest mortality

Correspondence to: Dr Xingang Peng, Department of Emergency General Surgery, The Affiliated Hospital of Qingdao University, 16 Jiangsu Road, Qingdao, Shandong 266555, P.R. China

E-mail: xingang_peng@163.com

Key words: gastric cancer, apoptosis, FSTL-1, STAT6 rates for this disease have been noted in East Asian countries, including Japan, South Korea and China (1-3). Although a marked decline in the incidence of gastric cancer has occurred in some regions, such as in Western countries, gastric cancer remains a major clinical challenge due to limited treatment methods, poor prognosis and poor early diagnosis $(4,5)$. Despite improvements being made in oncological treatment, such as in surgery, which is the most common therapeutic strategy, the prognosis of patients with gastric cancer remains poor, with a 5-year survival rate of $<25 \%$ (6).

Numerous molecular marker alterations are associated with gastric cancer, including the inactivation of tumor suppressor genes, such as APC, WNT signaling pathway regulator, cadherin 1, retinoblastoma, p53 and DCC netrin 1 receptor, and the activation of oncogenes, such as KRAS proto-oncogene, GTPase, erb-b2 receptor tyrosine kinase 2, hepatocyte growth factor receptor, $\beta$-catenin 1, cyclin E1 and fibroblast growth factor receptor $2(1,7,8)$. Kim et al observed that follistatin-like protein 1 (FSTL-1) is highly expressed in patients with gastric cancer; however, the function of FSTL-1 in cancer biology remains unknown (1). FSTL-1, also known as follistatin-related protein or transforming growth factor (TGF) $\beta$ stimulating clone-36, is a 308 -amino acid soluble extracellular glycoprotein, which is a member of the secreted protein acidic and rich in cysteine and follistatin families (9-12).

As a TGF- $\beta$ stimulating clone-36 protein, FSTL-1 is able to inhibit TGF- $\beta$ superfamily proteins and is secreted under inflammatory conditions. In addition, as a proinflammatory protein it is highly expressed and serves a role in inflammatory diseases, such as rheumatoid arthritis (13-15). Alongside its proinflammatory role, FSTL-1 serves roles in numerous pathological processes, such as fibrogenesis (16), vascularization (17), embryonic development (18-20), immunomodulation (21) and tumorigenesis (22). Furthermore, FSTL1 is associated with cell biology processes, including cell differentiation, migration, proliferation and apoptosis (23). Accumulating evidence has indicated that FSTL1 is widely expressed in cancer cells, including human lung cancer cells, clear-cell renal cell carcinoma cells, glioma cells and gastric cancer cells $(1,15,24,25)$.

Signal transducer and activator of transcription 6 (STAT6) belongs to the STAT family, which contains seven members, including STAT1, STAT2, STAT3, STAT4, STAT5a, STAT5b and STAT6 (26). The activation of STAT6 is tightly associated 
with inflammatory cytokines, such as interleukin (IL)-4 and IL-13 signaling (27). Jayakumar and Bothwell confirmed that STAT6 promotes intestinal tumorigenesis in a mouse model of adenomatous polyposis (28). Furthermore, Wang et al suggested that STAT6 is involved in the function of FSTL1 in dendritic cell-mediated immunity (29). Therefore, it was hypothesized that the proinflammatory protein FSTL-1 may mediate the expression of STAT6 in gastric cancer cells.

The present study aimed to determine the role and the mechanism of FSTL-1 in gastric cancer progression. The results revealed that FSTL-1 was highly expressed in gastric cancer cells, and knockdown of FSTL-1 resulted in gastric cancer cell growth inhibition and apoptosis promotion. In addition, the effects of FSTL-1 on gastric cancer cell biology were blocked by STAT6 overexpression.

\section{Materials and methods}

Cell culture. The human gastric cancer cell lines (AGS, MGC-803, SGC-7901, BGC-823 and MKN-45) and the human gastric mucosal epithelial cell line (GES-1) were obtained from American Type Culture Collection (Manassas, VA, USA). Cells were cultured in Dulbecco's modified Eagle's medium supplemented with $10 \%$ fetal bovine serum (Gibco; Thermo Fisher Scientific, Inc., Waltham, MA, USA) in a humidified incubator containing $5 \% \mathrm{CO}_{2}$ at $37^{\circ} \mathrm{C}$.

Cell transfection. For the construction of FSTL-1 knockdown cells, 25 pmol FSTL-1-specific small interfering RNA (siRNA; Shanghai GenePharma Co., Ltd., Shanghai, China) and a negative control siRNA (si-NC; Shanghai GenePharma Co., Ltd.) were transfected into MGC-803 and MKN45 cells using Lipofectamine $^{\circledR} 2000$ (Invitrogen; Thermo Fisher Scientific, Inc.), according to the manufacturer's protocol. Briefly, cells were seeded in 6-well plates at a density of $1 \times 10^{5}$ cells/well and transfection was performed once cells reached $60 \%$ confluence. Cells were transfected with the siRNAs at $37^{\circ} \mathrm{C}$ for $48 \mathrm{~h}$. The siRNA sequences were as follows: FSTL1 siRNA, sense 5'-GAAACUGCCAUCAAUAUUATT-3', anti-sense 5'-UAA UAUUGAUGGCAGUUUCTT-3'; and si-NC, sense 5'-UUC UCCGAACGUGUCACGUTT-3' and anti-sense 5'-ACG UGACACGUUCGGAGAATT-3'. For transient expression of STAT6, $60 \mathrm{nM}$ pcDNA3.1-STAT6 or an empty vector (pcDNA3.1) were co-transfected with FSTL-1 siRNA or si-NC into MGC-803 and MKN45 cells using Lipofectamine ${ }^{\circledR} 2000$ (Invitrogen; Thermo Fisher Scientific, Inc.). Briefly, cells were seeded in 6-well plates at a density of $1 \times 10^{5}$ cells/well and transfection was performed once reached at $60 \%$ confluence. The cells were transfected at $37^{\circ} \mathrm{C}$ for $48 \mathrm{~h}$.

Cell survival assay. MGC-803 and MKN45 cells were cultured and transfected as aforementioned. Cell viability was determined using the CellTiter-Glo ${ }^{\circledR}$ Luminescent Cell Viability Assay (Promega Corporation, Madison, WI, USA), according to the manufacturer's protocol.

Cell cytotoxicity assay. MGC-803 and MKN45 cell cytotoxicity was measured using an lactate dehydrogenase (LDH) assay, as previously reported (30). LDH release from cells transfected with FSTL-1 siRNA for $48 \mathrm{~h}$ was measured using a cytotoxicity detection kit (Roche Applied Science, Penzberg, Germany), according to the manufacturer's protocol.

Cell apoptosis. MGC-803 and MKN45 cells were cultured and transfected as aforementioned. Cell apoptosis was ascertained using the Cell Death Detection ELISA assay (cat. no. 11544675001; Roche Diagnostics GmbH, Mannheim, Germany), according to the manufacturer's protocol. The amount of histone-complexed DNA fragments in MGC-803 and MKN45 cells was quantified, in order to analyze apoptosis. The absorbance of MGC-803 and MKN45 cells was measured using an ELISA reader at $405 \mathrm{~nm}$.

Reverse transcription-quantitative polymerase chain reaction $(R T-q P C R)$. Total RNA was extracted from MGC-803 and MKN45 cells using TRIzol ${ }^{\circledR}$ reagent (Invitrogen; Thermo Fisher Scientific, Inc.), according to the manufacturer's protocol, and the concentration of RNA was determined using a spectrophotometer. cDNA was generated using a High-Capacity cDNA RT kit (Thermo Fisher Scientific, Inc.), according to the manufacturer's protocol. The relative mRNA expression levels of FSTL-1 were determined using an Applied Biosystems 7500 Real Time PCR system (Applied Biosystems; Thermo Fisher Scientific, Inc.) with SYBR Green PCR Master Mix (Thermo Fisher Scientific, Inc); results were quantified using the $\left(2^{-\Delta \Delta \mathrm{Cq}}\right)$ method (31). $\beta$-actin was used as a control gene. The following primers were used in the present study: FSTL-1, forward 5'-CCT GTGTGTGGCAGTAATGG-3' and reverse 5'-TCAGGAGGG TTGAAAGATGG-3'; and $\beta$-actin, forward 5'-GCACCACAC CTTCTACAATG-3' and reverse 5'-TGCTTGCTGATCCAC ATCTG-3'. Cycling conditions were as follows: Initial denaturation at $95^{\circ} \mathrm{C}$ for $5 \mathrm{~min}$, followed by 38 cycles of denaturation at $95^{\circ} \mathrm{C}$ for $15 \mathrm{sec}$, annealing at $58^{\circ} \mathrm{C}$ for $30 \mathrm{sec}$ and extension at $55^{\circ} \mathrm{C}$ for $30 \mathrm{sec}$, and a final extension step at $72^{\circ} \mathrm{C}$ for $1 \mathrm{~min}$.

Western blot analysis. MGC-803 and MKN45 cells were transfected with FSTL-1 siRNA, or co-transfected with FSTL-1 siRNA and pcDNA3.1-STAT6 and their corresponding controls for $48 \mathrm{~h}$. Total proteins were extracted using radioimmunoprecipitation assay (RIPA) buffer (Thermo Fisher Scientific, Inc.) and the concentration was determined by using the Bio-Rad Protein Assay kit (Bio-Rad Laboratories, Inc., Hercules, CA, USA). Proteins ( $50 \mu \mathrm{g} /$ lane) were separated by $12 \%$ SDS-PAGE and were electrophoretically transferred to nitrocellulose membranes. The membranes were blocked with $5 \%$ nonfat dry milk for $1 \mathrm{~h}$ at room temperature. Subsequently, the membranes were incubated with specific antibodies, including FSTL-1 (cat. no. ab71548; 1:1,000; Abcam, Cambridge, MA, USA), anti- $\beta$-actin (cat. no. ab8226; 1:1,000; Abcam), phosphorylated-STAT6 (cat. no. ab28829; 1:500; Abcam) and STAT6 (cat. no. ab227497; 1:1,000; Abcam) overnight at $4^{\circ} \mathrm{C}$. Subsequently, the membrane was incubated with a horseradish peroxidase-conjugated goat anti-rabbit immunoglobulin $\mathrm{G}$ secondary antibody (cat. no. ab6721; 1:5,000; Abcam) for $1 \mathrm{~h}$ at room temperature. An enhanced chemiluminescence detection kit (Amersham; GE Healthcare, Chicago, IL, USA) was used to detect immunoreactive proteins. $\beta$-actin was used as control.

Caspase-3/9 activity. Caspase-3/9 activity was assessed using colorimetric substrates, according to the methods 


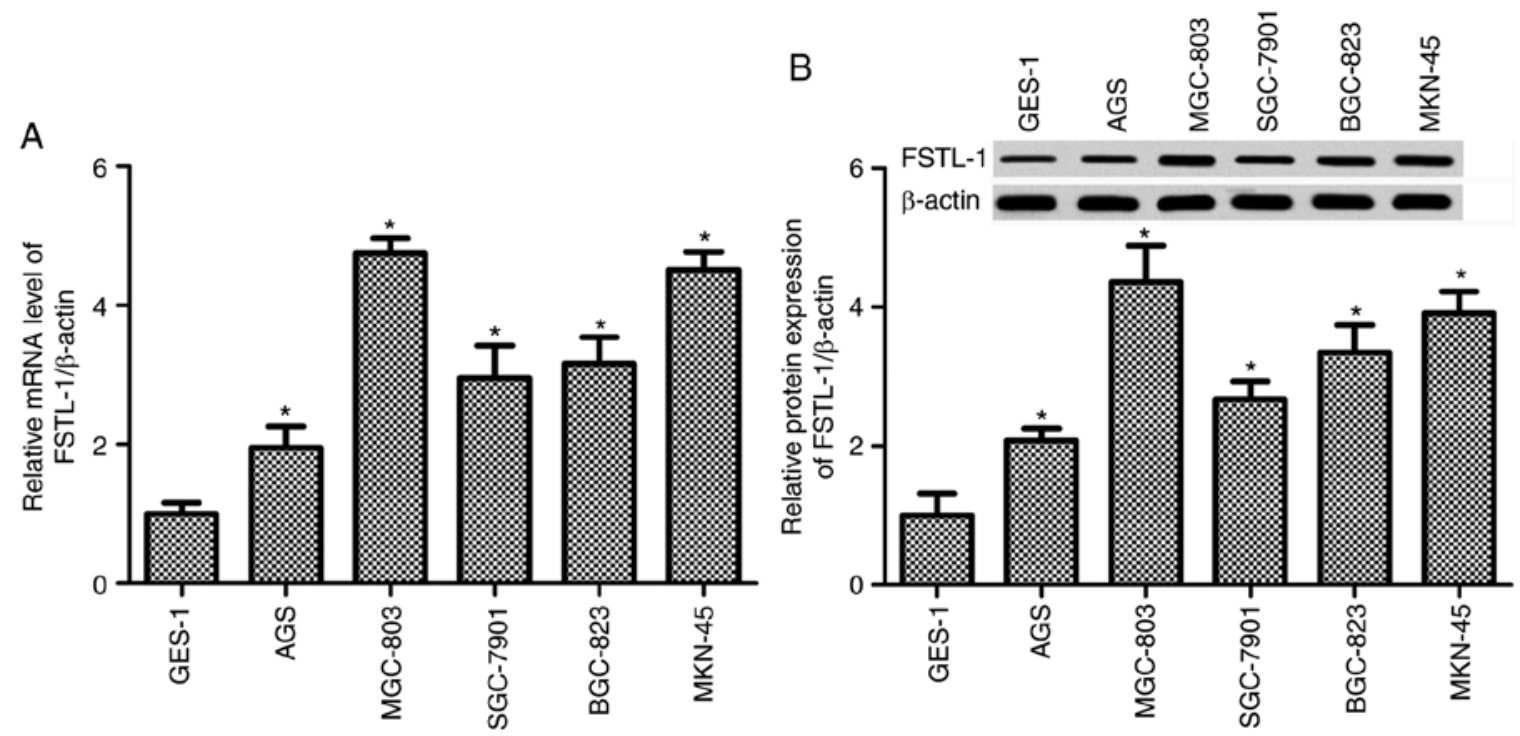

Figure 1. Expression of FSTL-1 was increased in gastric cancer cells. (A) FSTL-1 mRNA expression was determined by reverse transcription-quantitative polymerase chain reaction. (B) Western blotting was used to measure the protein expression levels of FSTL-1. Five gastric cancer cell lines (AGS, MGC-803, SGC-7901, BGC-823 and MKN-45) and the control gastric mucosal epithelial cell line (GES-1) were used in this study, and the mean fold changes in FSTL-1 mRNA and protein expression are shown. All experiments were performed at least three times in triplicate. " $\mathrm{P}<0.05$ compared with the GES-1 group. FSTL-1, follistatin-like protein 1.
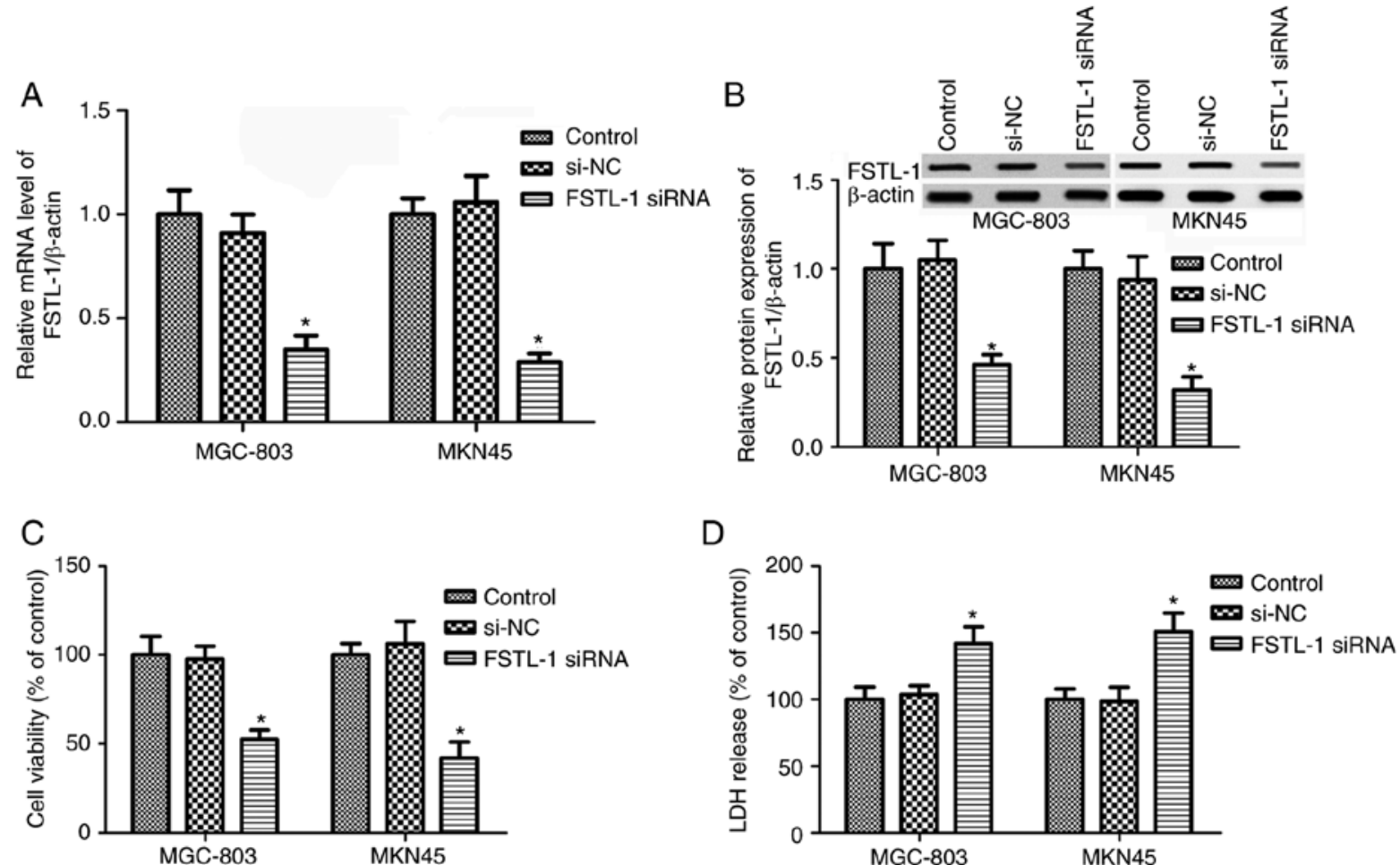

Figure 2. Effects of FSTL-1 inhibition on MGC-803 and MKN45 cell survival and cytotoxicity. (A) FSTL-1 mRNA expression was determined by reverse transcription-quantitative polymerase chain reaction. (B) Western blotting was used to measure the protein expression levels of FSTL-1. (C) Cell survival was measured using the CellTiter-Glo ${ }^{\circledast}$ Luminescent Cell Viability Assay. (D) Cytotoxicity was assessed using the LDH release method. MGC-803 and MKN45 cells were transfected with FSTL-1 siRNA and si-NC using Lipofectamine ${ }^{\circledR} 2000$ for $48 \mathrm{~h}$. All experiments were performed at least three times in triplicate. ${ }^{*} \mathrm{P}<0.05$ compared with the control group. FSTL-1, follistatin-like protein 1; LDH, lactate dehydrogenase; NC, negative control; si/siRNA, small interfering RNA.

described previously (32). MGC-803 and MKN45 cells were lysed with RIPA lysis buffer, collected and incubated with colorimetric caspase-3 substrate (Ac-DEVD-Pna; Promega Corporation) and caspase-9 substrate (Ac-LEHD-Pna; Promega Corporation) at $37^{\circ} \mathrm{C}$ for $3 \mathrm{~h}$ in dark. The activity of caspase-3/9 in MGC-803 and MKN45 cells was then measured using a spectrophotometer at a wavelength of $405 \mathrm{~nm}$.

Statistical analysis. All experiments were conducted at least three times in triplicate. SPSS 19.0 (SPSS, Inc., Chicago, 

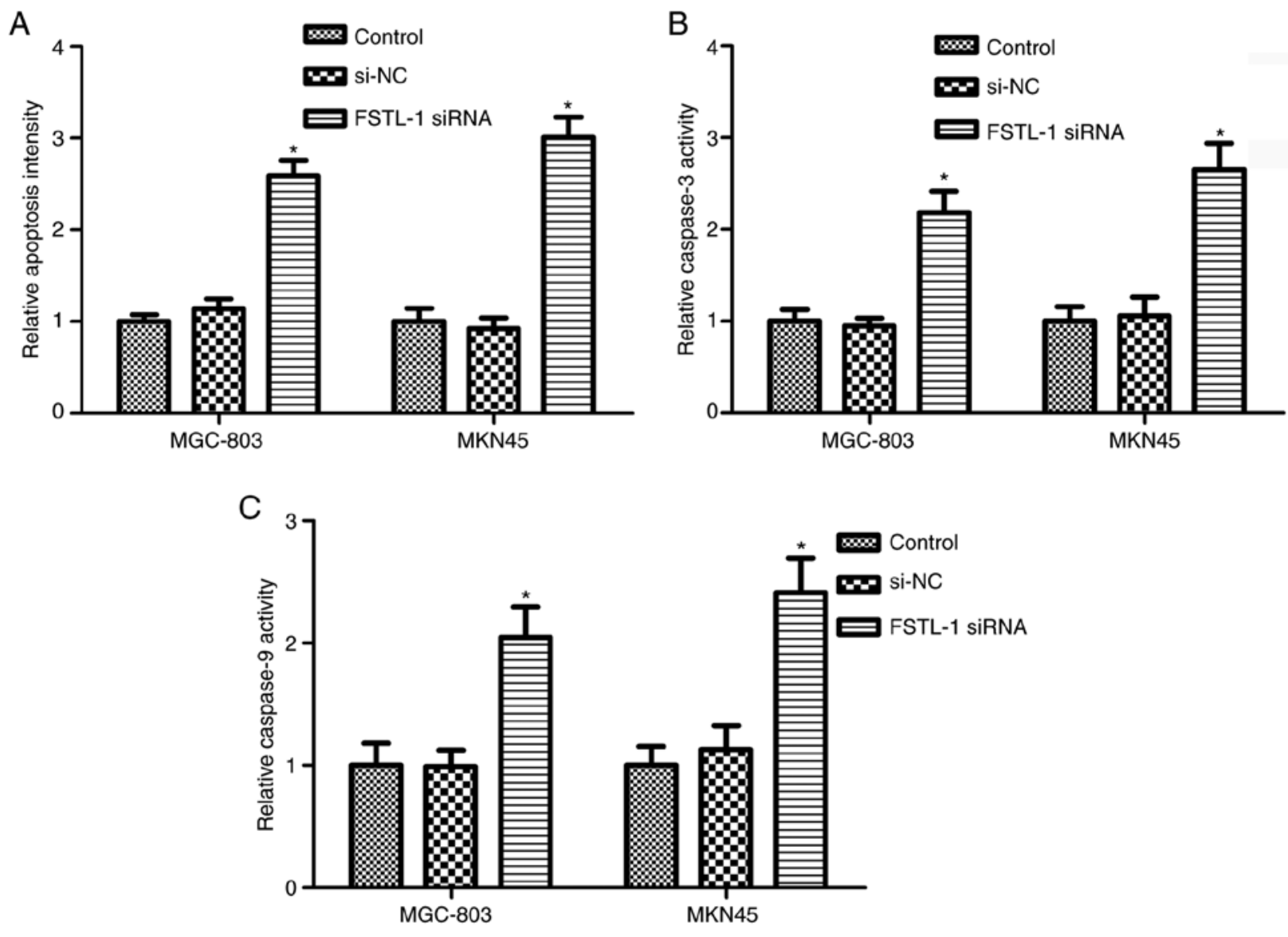

Figure 3. FSTL-1 depletion promotes cell apoptosis. (A) Cell apoptosis was determined using the Cell Death Detection ELISA assay. (B) Caspase-3 and (C) caspase-9 activity was assessed using respective colorimetric substrates. MGC-803 and MKN45 cells were transfected with FSTL-1 siRNA and si-NC using Lipofectamine ${ }^{\circledR} 2000$ for $48 \mathrm{~h}$. All experiments were performed at least three times in triplicate. ${ }^{*} \mathrm{P}<0.05$ compared with the control group. FSTL-1, follistatin-like protein 1; NC, negative control; si/siRNA, small interfering RNA.

IL, USA) was used for data analyses. Data are presented as the means \pm standard deviation. Statistical analyses were performed by one-way analysis of variance followed by Fisher's least significant difference. $\mathrm{P}<0.05$ was considered to indicate a statistically significant difference.

\section{Results}

FSTL-1 is highly expressed in gastric cancer cells. The present study demonstrated that compared with in the control GES-1 gastric mucosal epithelial cell line, the mRNA expression levels of FSTL-1 in the gastric cancer cell lines, AGS, MGC-803, SGC-7901, BGC-823 and MKN-45, were significantly enhanced $(\mathrm{P}<0.05$, Fig. $1 \mathrm{~A})$. The protein expression levels of FSTL-1 in the cells were detected by western blotting, which was normalized to $\beta$-actin. The results revealed that FSTL-1 protein expression was increased in all gastric cancer cell lines compared with in the GES-1 cells $(\mathrm{P}<0.05$, Fig. 1B). Expression was highest in MGC-803 and MKN45 cells; therefore, these two cell lines were used in the subsequent experiments (Fig. 1).

FSTL-1 inhibition reduces $M G C-803$ and MKN45 cell survival and induces cytotoxic effects. To determine the function of FSTL-1 in gastric cancer cell biology, FSTL-1 was inhibited in MGC-803 and MKN45 cells by transfection with
FSTL-1 siRNA. The results suggested that FSTL-1 mRNA and protein expression levels were decreased in MGC-803 and MKN45 cells post-transfection with FSTL-1 siRNA $\left(\mathrm{P}<0.05\right.$, Fig. $2 \mathrm{~A}$ and B). Subsequently, the CellTiter-Glo ${ }^{\circledR}$ Luminescent Cell Viability assay was performed to determine the effects of FSTL-1 depletion on MGC-803 and MKN45 cells. As shown in Fig. 2C, compared with in the control and si-NC groups, FSTL-1 silencing markedly reduced the viability of MGC-803 and MKN45 cells $(\mathrm{P}<0.05)$. Further studies confirmed that FSTL-1 siRNA transfection exhibited significant cytotoxic effects on MGC-803 and MKN45 cells compared with the control group; there were no significant differences between the si-NC group and the control group ( $\mathrm{P}>0.05$, Fig. 2D).

FSTL-1 depletion promotes cell apoptosis and mediates apoptosis-associated gene activity. Since FSTL-1 silencing inhibited MGC-803 and MKN45 cell viability and induced cytotoxic effects, the Cell Death Detection ELISA assay and caspase-3/9 activity assay were performed to determine the effects of FSTL-1 depletion on MGC-803 and MKN45 cell apoptosis. As shown in Fig. 3A, FSTL-1 knockdown in MGC-803 and MKN45 cells for $48 \mathrm{~h}$ resulted in an increase in the cell apoptotic ratio compared with in the control group $(\mathrm{P}<0.05)$. To validate the results, caspase- 3 and caspase- 9 activity was determined. The results indicated that inhibiting 

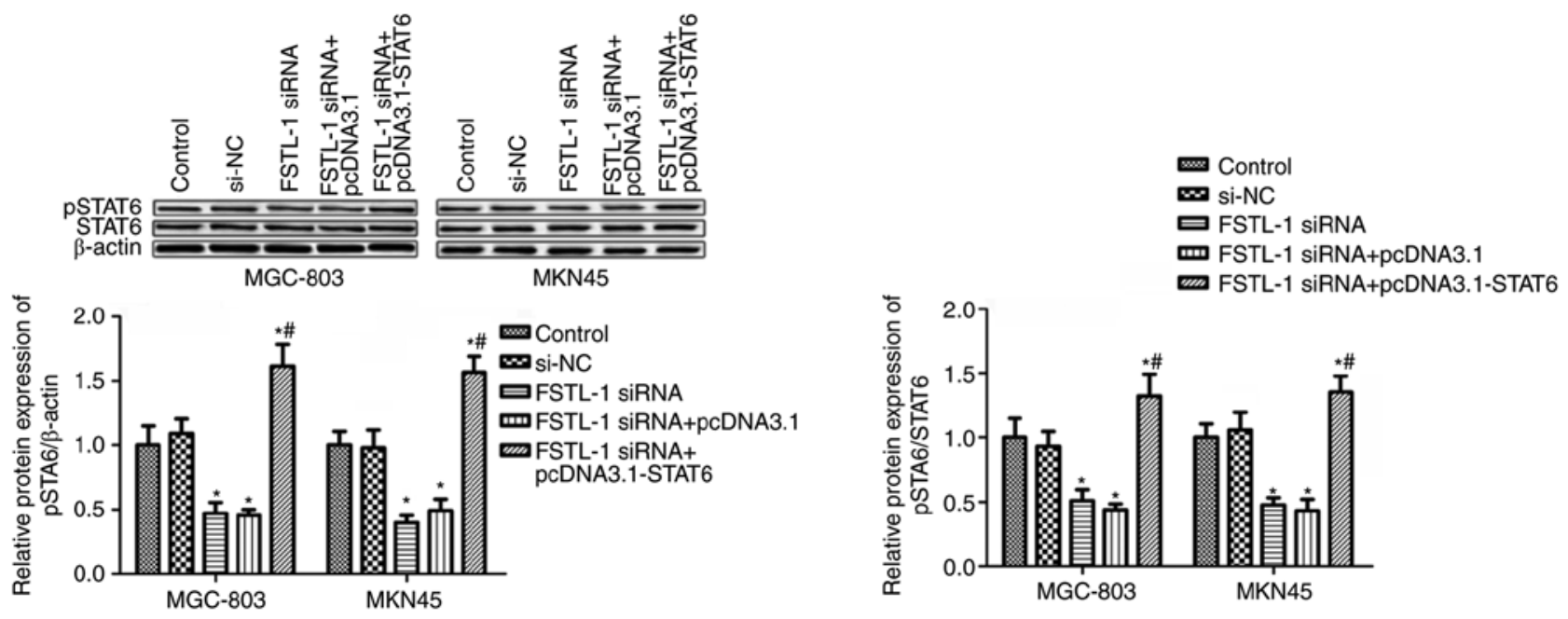

Figure 4. FSTL-1 knockdown inhibits STAT6 phosphorylation in gastric cancer cells. STAT6 phosphorylation and total STAT6 expression were determined by western blotting. MGC-803 and MKN45 cells were transfected with FSTL-1 siRNA, or were co-transfected with FSTL-1 siRNA and pcDNA3.1- STAT6 or empty vector pcDNA3.1 using Lipofectamine ${ }^{\circledR} 2000$ for $48 \mathrm{~h}$. All experiments were performed at least three times in triplicate. ${ }^{*}<<0.05$ compared with the control group, " $\mathrm{P}<0.05$ compared with the FSTL-1 siRNA group. FSTL-1, follistatin-like protein 1; NC, negative control; pSTAT6, phosphorylated-STAT6; si/siRNA, small interfering RNA; STAT6, signal transducer and activator of transcription 6.

\section{A}

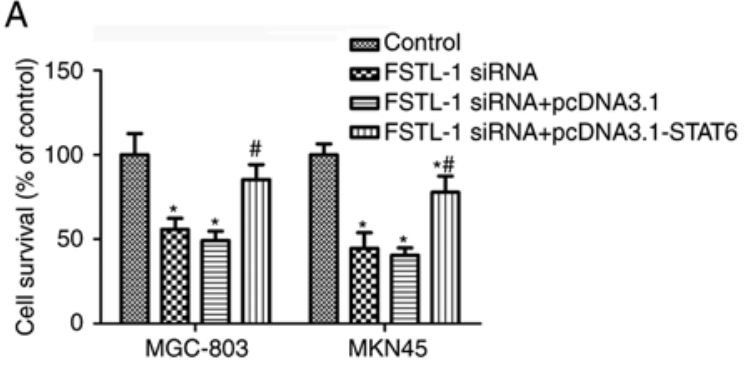

C

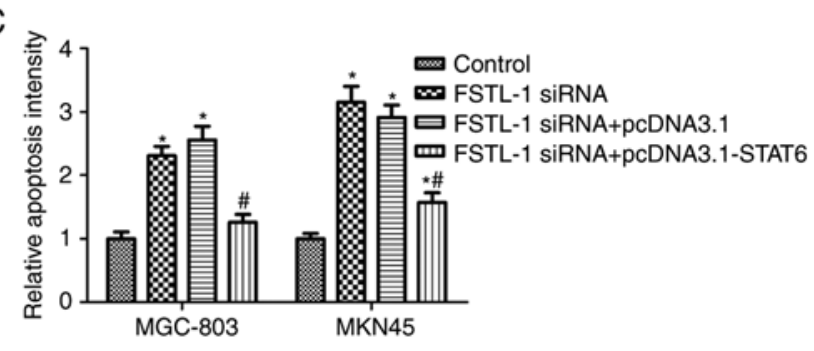

B

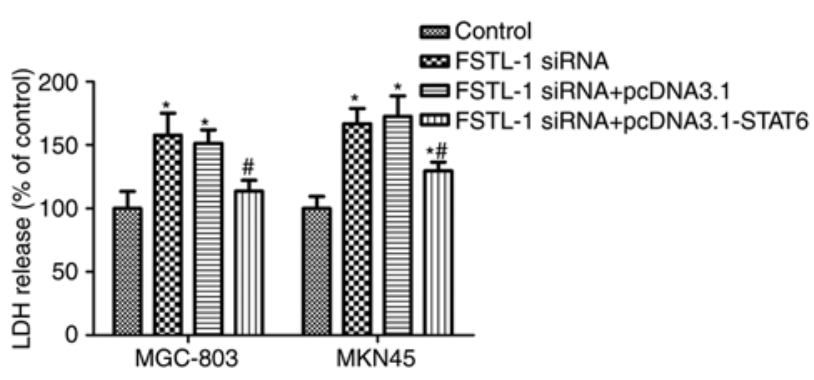

D

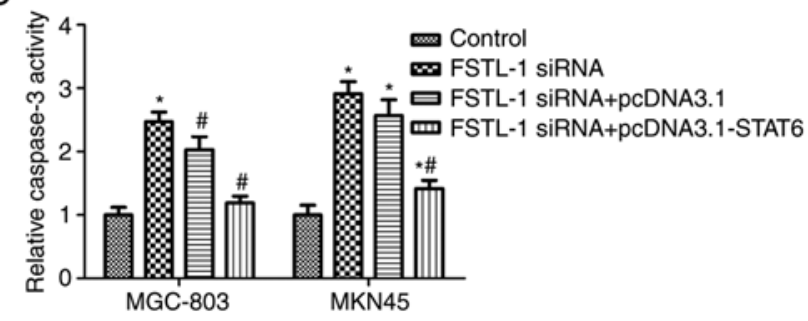

E

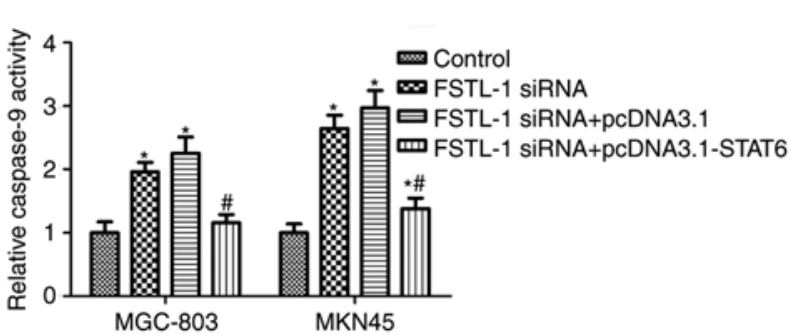

Figure 5. Effects of FSTL-1 knockdown on gastric cancer cells are dependent on inhibition of STAT6 phosphorylation. (A) Cell survival was measured using the CellTiter-Glo ${ }^{\circledR}$ Luminescent Cell Viability Assay. (B) Cytotoxicity was assessed according to the LDH release method. (C) Cell apoptosis was detected using the Cell Death Detection ELISA assay. (D) Caspase-3 and (E) caspase-9 activity was assessed using respective colorimetric substrates. MGC-803 and MKN45 cells were transfected with FSTL-1 siRNA, or were co-transfected with FSTL-1 siRNA and pcDNA3.1-STAT6 or empty vector pcDNA3.1 using Lipofectamine ${ }^{\circledR} 2000$ for $48 \mathrm{~h}$. All experiments were performed at least three times in triplicate. ${ }^{*} \mathrm{P}<0.05$ compared with the control group, ${ }^{\#} \mathrm{P}<0.05$ compared with the FSTL-1 siRNA group. FSTL-1, follistatin-like protein 1; LDH, lactate dehydrogenase; si/siRNA, small interfering RNA; STAT6, signal transducer and activator of transcription 6.

the expression of FSTL-1 markedly increased caspase-3 and caspase-9 activity in MGC-803 and MKN45 cells $(\mathrm{P}<0.05$,
Fig. 3B and C). These results suggested that FSTL-1 may serve fundamental roles in gastric cancer cell survival and apoptosis. 
FSTL-1 silencing inhibits STAT6 phosphorylation in gastric cancer cells. FSTL-1 is an inflammatory cytokine regulator; in addition, inflammatory cytokines can activate STAT6 $(14,33)$. Therefore, it was hypothesized that FSTL-1 may mediate STAT6 phosphorylation. The results of a western blot analysis indicated that, compared with in the control group, FSTL-1 knockdown reduced STAT6 phosphorylation in MGC-803 and MKN45 cells $(\mathrm{P}<0.05)$ normalized to total STAT6 and the loading control $\beta$-actin, whereas transfection with si-NC had no obvious effect on STAT6 phosphorylation ( $\mathrm{P}>0.05$, Fig. 4). Furthermore, to confirm FSTL-1 knockdown decreased phosphorylation of STAT6, total STAT6 levels were determined; the results revealed that FSTL-1 depletion had no obvious effect on total STAT6 levels (Fig. 4).

FSTL1 knockdown is implicated in gastric cancer cell apoptosis via the STAT6 pathway. To determine whether STAT6 is involved in FSTL-1 knockdown-induced cell apoptosis, MGC-803 and MKN45 cells were co-transfected with FSTL-1 siRNA and pcDNA3.1-STAT6. Western blotting suggested that pcDNA3.1-STAT6 transfection increased STAT6 phosphorylation compared with in the FSTL-1 siRNA group (Fig. 4A). Transfection with FSTL1 siRNA significantly inhibited MGC-803 and MKN45 cell survival and induced cytotoxicity, both of which were rescued by pcDNA3.1-STAT6 transfection (Fig. 5A and B). Furthermore, pcDNA3.1-STAT6 transfection reversed the effects of FSTL-1 siRNA on MGC-803 and MKN45 cell apoptosis and caspase-3/9 activity (Fig. 5C-E). These results indicated that FSTL1 knockdown induced cell apoptosis, which may be dependent on inhibition of STAT6 phosphorylation.

\section{Discussion}

Gastric cancer is a common cause of cancer-associated mortality worldwide (34). Early diagnosis is a main challenge for cancer treatment, and molecular markers serve important roles in cancer diagnosis and treatment. In the present study, FSTL1 was revealed as a potential useful biomarker for gastric cancer diagnosis and therapy.

The secreted glycoprotein FSTL-1 is associated with several physiological and pathological processes, including tumorigenesis $(22,35)$. However, the function of FSTL-1 in cancer progression remains controversial. A recent study demonstrated that FSTL-1 knockdown with short hairpin RNA (shRNA) sequences increases lung cancer cell growth, migration and invasion, and decreases apoptosis (36). In addition, increasing FSTL-1 levels via the melanoma antigen-A11 and androgen receptor increases growth and progression of castration-resistant/recurrent prostate cancer (37). Jin et al suggested that FSTL-1 overexpression promotes glioma cell proliferation, cell cycle progression and colony formation, whereas FSTL-1 depletion inhibits these processes (25). Furthermore, FSTL-1 has been revealed to be highly expressed in patients with gastric cancer (1). The present results were in accordance with some of these previous reports; the findings confirmed that FSTL-1 expression was increased in gastric cancer cells compared with in control cells, and knockdown of FSTL-1 inhibited gastric cancer cell growth and promoted apoptosis. It has been suggested that FSTL-1 antibodies may be useful in FSTL-high cells to inhibit FSTL expression, and previous evidence has suggested that FSTL plasmid-induced overexpression or shRNA/siRNA knockdown studies could significantly promote or suppress FSTL expression $(25,38)$. We aim to use FSTL-1 commercial recombinant proteins and antibodies to study its function in future studies.

FSTL-1 has been reported to mediate inflammatory cytokine expression and evidence has suggested that inflammatory cytokines, such as IL-4, IL-5 and IL-13, may activate STAT6 $(14,33)$. Furthermore, it has been demonstrated that FSTL-1 is involved in dendritic cell-based immunity in patients with nasopharyngeal carcinoma, and is associated with the activation of STAT6 (29). Consistent with these previous reports, the present study revealed that FSTL-1 knockdown in gastric cancer cells markedly suppressed the activation of STAT6. STAT6 is a member of the STAT family, which has fundamental roles in cancer, such as breast cancer (39), non-small-cell lung cancer (40), melanoma (27), hepatocellular carcinoma (41) and colon cancer (42). A recent study indicated that inhibition of STAT6 activation serves inhibitory roles in gastric cancer cell proliferation and invasion (43). In agreement with these earlier reports, the present study demonstrated that STAT6 was involved in the functions of FSTL-1 in gastric cancer cell growth and apoptosis, and the effects of FSTL-1 knockdown were reversed with STAT6 overexpression.

To the best of our knowledge, the present study is the first to report on the function and mechanism of FSTL-1 in gastric cancer development. In the present study, the effects of FSTL-1 knockdown on cancer inhibition were only investigated in vitro, and the lack of in vivo animal experiments is a main limitation to the study. We aim to study the expression and function of FSTL-1 in gastric cancer tissues and in a mouse model in future studies. In conclusion, the present study revealed that FSTL-1 was highly expressed in gastric cancer cells, and knockdown of its expression induced tumor inhibitory effects via the promotion of cell apoptosis and the suppression of cell survival. STAT6 was also confirmed to be involved in the effects of FSTL-1 on cancer progression.

\section{Acknowledgements}

Not applicable.

\section{Funding}

No funding was received.

\section{Availability of data and materials}

All data generated or analyzed during this study are included in this published article.

\section{Authors' contributions}

XP designed the study and obtained data. PW, SL, YJ and CW obtained and analyzed data. XP, SL and YJ wrote the manuscript. All authors read and approved the final manuscript. 


\section{Ethics approval and consent to participate}

Not applicable.

\section{Patient consent for publication}

Not applicable.

\section{Competing interests}

The authors declare that they have no competing interests.

\section{References}

1. Kim H, Eun JW, Lee H, Nam SW, Rhee H, Koh KH and Kim H: Gene expression changes in patient-matched gastric normal mucosa, adenomas, and carcinomas. Exp Mol Pathol 90: 201-209, 2011.

2. Ferlay J, Soerjomataram I, Dikshit R, Eser S, Mathers C, Rebelo M, Parkin DM, Forman D and Bray F: Cancer incidence and mortality worldwide: Sources, methods and major patterns in GLOBOCAN 2012. Int J Cancer 136: E359-E386, 2015.

3. Togo R, Ishihara K, Mabe K, Oizumi H, Ogawa T, Kato M, Sakamoto N, Nakajima S, Asaka $M$ and Haseyama $M$ : Preliminary study of automatic gastric cancer risk classification from photofluorography. World J Gastrointest Oncol 10: 62-70, 2018.

4. Parkin DM, Bray F, Ferlay J and Pisani P: Global cancer statistics, 2002. CA Cancer J Clin 55: 74-108, 2005.

5. De Manzoni G, Marrelli D, Baiocchi GL, Morgagni P, Saragoni L, Degiuli M, Donini A, Fumagalli U, Mazzei MA, Pacelli F, et al The Italian research group for gastric cancer (GIRCG) guidelines for gastric cancer staging and treatment: 2015. Gastric Cancer 20: 20-30, 2017.

6. Brenner H: Long-term survival rates of cancer patients achieved by the end of the 20th century: A period analysis. Lancet 360 : 1131-1135, 2002.

7. Werner M, Becker KF, Keller G and Höfler H: Gastric adenocarcinoma: Pathomorphology and molecular pathology. J Cancer Res Clin Oncol 127: 207-216, 2001.

8. Tahara E: Genetic pathways of two types of gastric cancer. IARC Sci Publ 157: 327-349, 2004.

9. Wei Q, Wang YN, Liu HY, Yang J, Yang CY, Liu M, Liu YF, Yang $\mathrm{P}$ and Liu $\mathrm{ZH}$ : The expression and role of activin A and follistatin in heart failure rats after myocardial infarction. Int $\mathrm{J}$ Cardiol 168: 2994-2997, 2013.

10. Shibanuma M, Mashimo J, Mita A, Kuroki T and Nose K: Cloning from a mouse osteoblastic cell line of a set of transforming-growth-factor-beta 1-regulated genes, one of which seems to encode a follistatin-related polypeptide. Eur J Biochem 217: 13-19, 1993.

11. Sylva M, Moorman AF and van den Hoff MJ: Follistatin-like 1 in vertebrate development. Birth Defects Res C Embryo Today 99: 61-69, 2013.

12. Prakash S, Borreguero LJJ, Sylva M, Flores Ruiz L, Rezai F, Gunst QD, de la Pompa JL, Ruijter JM and van den Hoff MJB: Deletion of Fstl1 (follistatin-like 1) from the endocardial/endothelial lineage causes mitral valve disease. Arterioscler Thromb Vasc Biol 37: e116-e130, 2017.

13. Kawabata D, Tanaka M, Fujii T, Umehara H, Fujita Y, Yoshifuji H, Mimori T and Ozaki S: Ameliorative effects of follistatin-related protein/TSC-36/FSTL1 on joint inflammation in a mouse model of arthritis. Arthritis Rheum 50: 660-668, 2004.

14. Miyamae T, Marinov AD, Sowders D, Wilson DC, Devlin J, Boudreau R, Robbins P and Hirsch R: Follistatin-like protein-1 is a novel proinflammatory molecule. J Immunol 177: 4758-4762, 2006.

15. Bae K, Park KE, Han J, Kim J, Kim K and Yoon KA: Mitotic cell death caused by follistatin-like 1 inhibition is associated with up-regulated Bim by inactivated Erk1/2 in human lung cancer cells. Oncotarget 7: 18076-18084, 2016.

16. Dong Y, Geng Y, Li L, Li X, Yan X, Fang Y, Li X, Dong S, Liu X, Li X, et al: Blocking follistatin-like 1 attenuates bleomycin-induced pulmonary fibrosis in mice. J Exp Med 212: 235-252, 2015
17. Ouchi N, Oshima Y, Ohashi K, Higuchi A, Ikegami C, Izumiya $Y$ and Walsh K: Follistatin-like 1, a secreted muscle protein, promotes endothelial cell function and revascularization in ischemic tissue through a nitric-oxide synthase-dependent mechanism. J Biol Chem 283: 32802-32811, 2008

18. Geng Y, Dong Y, Yu M, Zhang L, Yan X, Sun J, Qiao L, Geng H, Nakajima M, Furuichi T, et al: Follistatin-like 1 (Fstl1) is a bone morphogenetic protein (BMP) 4 signaling antagonist in controlling mouse lung development. Proc Natl Acad Sci USA 108: 7058-7063, 2011

19. Sylva M, Li VS, Buffing AA, van Es JH, van den Born M, van der Velden S, Gunst Q, Koolstra JH, Moorman AF, Clevers H and van den Hoff MJ: The BMP antagonist follistatin-like 1 is required for skeletal and lung organogenesis. PLoS One 6: e22616, 2011.

20. Xu J, Qi X, Gong J, Yu M, Zhang F, Sha H and Gao X: Fstll antagonizes BMP signaling and regulates ureter development. PLoS One 7: e32554, 2012.

21. Murakami K, Tanaka M, Usui T, Kawabata D, Shiomi A, Iguchi-Hashimoto M, Shimizu M, Yukawa N, Yoshifuji H, Nojima $T$, et al: Follistatin-related protein/follistatin-like 1 evokes an innate immune response via CD14 and toll-like receptor 4. FEBS Lett 586: 319-324, 2012.

22. Zhou X, Xiao X, Huang T, Du C, Wang S, Mo Y, Ma N, Murata M, $\mathrm{Li} \mathrm{B}$, Wen W, et al: Epigenetic inactivation of follistatin-like 1 mediates tumor immune evasion in nasopharyngeal carcinoma. Oncotarget 7: 16433-16444, 2016.

23. Liu X, Liu Y, Li X, Zhao J, Geng Y and Ning W: Follistatin like-1 (Fstl1) is required for the normal formation of lung airway and vascular smooth muscle at birth. PLoS One 12: e0177899, 2017.

24. Liu Y, Tan X, Liu W, Chen X, Hou X, Shen D, Ding Y, Yin J, Wang L, Zhang $\mathrm{H}$, et al: Follistatin-like protein 1 plays a tumor suppressor role in clear-cell renal cell carcinoma. Chin J Cancer 37: 2, 2018.

25. Jin X, Nie E, Zhou X, Zeng A, Yu T, Zhi T, Jiang K, Wang Y, Zhang J and You Y: Fstll promotes glioma growth through the BMP4/Smad1/5/8 signaling pathway. Cell Physiol Biochem 44: 1616-1628, 2017.

26. Ihle JN: The Stat family in cytokine signaling. Curr Opin Cell Biol 13: 211-217, 2001.

27. Son DJ, Jung YY, Park MH, Lee HL, Song MJ, Yoo HS, Hwang DY, Han SB and Hong JT: Activated natural killer cells mediate the suppressive effect of interleukin-4 on tumor development via STAT6 activation in an atopic condition melanoma model. Neoplasia 19: 537-548, 2017.

28. Jayakumar A and Bothwell ALM: Stat6 promotes intestinal tumorigenesis in a mouse model of adenomatous polyposis by expansion of MDSCs and inhibition of cytotoxic CD8 response. Neoplasia 19: 595-605, 2017.

29. Wang H, Huang S, Wu S, Yin S, Tang A and Wen W: Follistatin-like protein-1 upregulates dendritic cell-based immunity in patients with nasopharyngeal carcinoma. J Interferon Cytokine Res 37: 494-502, 2017.

30. Hussain S, Kodavanti PP, Marshburg JD, Janoshazi A, Marinakos SM, George M, Rice A, Wiesner MR and Garantziotis S: Decreased uptake and enhanced mitochondrial protection underlie reduced toxicity of nanoceria in human monocyte-derived macrophages. J Biomed Nanotechnol 12: 2139-2150, 2016

31. Livak KJ and Schmittgen TD: Analysis of relative gene expression data using real-time quantitative PCR and the 2(-Delta Delta C(T)) method. Methods 25: 402-408, 2001.

32. Yadav V, Varshney P, Sultana S, Yadav J and Saini N: Moxifloxacin and ciprofloxacin induces S-phase arrest and augments apoptotic effects of cisplatin in human pancreatic cancer cells via ERK activation. BMC Cancer 15: 581, 2015.

33. Miyake T, Miyake T, Sakaguchi M, Nankai H, Nakazawa T and Morishita R: Prevention of asthma exacerbation in a mouse model by simultaneous inhibition of NF- $\mathrm{KB}$ and STAT6 activation using a chimeric decoy strategy. Mol Ther Nucleic Acids 10: $159-169,2018$.

34. Mimura K, The JL, Okayama H, Shiraishi K, Kua LF, Koh V, Smoot DT, Ashktorab H, Oike T, Suzuki Y, et al: PD-L1 expression is mainly regulated by interferon gamma associated with JAK-STAT pathway in gastric cancer. Cancer Sci 109: 43-53, 2018.

35. Shimasaki S, Koga M, Esch F, Cooksey K, Mercado M, Koba A, Ueno N, Ying SY, Ling N and Guillemin R: Primary structure of the human follistatin precursor and its genomic organization. Proc Natl Acad Sci USA 85: 4218-4222, 1988. 
36. Ni X, Cao X, Wu Y and Wu J: FSTL1 suppresses tumor cell proliferation, invasion and survival in non-small cell lung cancer. Oncol Rep 39: 13-20, 2018.

37. Su S, Parris AB, Grossman G, Mohler JL, Wang Z and Wilson EM: Up-regulation of follistatin-like 1 by the androgen receptor and melanoma antigen-A11 in prostate cancer. Prostate 77: 505-516, 2017.

38. Hirsch R and Wilson DC: Follistatin-like protein-1 as a biomarker for inflammatory disorders. US Patent 8,741,584. Filed February 4, 2013; issued June 2, 2014.

39. Binnemars-Postma K, Bansal R, Storm G and Prakash J: Targeting the Stat6 pathway in tumor-associated macrophages reduces tumor growth and metastatic niche formation in breast cancer. Faseb J 32: 969-978, 2018.

40. Pastuszak-Lewandoska D, Domańska-Senderowska D Kordiak J, Antczak A, Czarnecka KH, Migdalska-Sęk M, Nawrot E, Kiszałkiewicz JM and Brzeziańska-Lasota E: Immunoexpression analysis of selected JAK/STAT pathway molecules in patients with non- small-cell lung cancer. Pol Arch Intern Med 127: 758-764, 2017.
41. Qing T, Yamin Z, Guijie W, Yan J and Zhongyang S: STAT6 silencing induces hepatocellular carcinoma-derived cell apoptosis and growth inhibition by decreasing the RANKL expression. Biomed Pharmacother 92: 1-6, 2017.

42. Leon-Cabrera SA, Molina-Guzman E, Delgado-Ramirez YG, Vázquez-Sandoval A, Ledesma-Soto Y, Pérez-Plasencia CG, Chirino YI, Delgado-Buenrostro NL, Rodriguez-Sosa M, Vaca-Paniagua F, et al: Lack of STAT6 attenuates inflammation and drives protection against early steps of colitis-associated colon cancer. Cancer Immunol Res 5: 385-396, 2017.

43. Lu G, Shi W and Zheng H: Inhibition of STAT6/anoctamin-1 activation suppresses proliferation and invasion of gastric cancer cells. Cancer Biother Radiopharm 33: 3-7, 2018. 